\title{
Study of endometrial Status of Patients with Abnormal Uterine Bleeding in Patan Hospital
}

\section{Shrestha $S^{1}$ Sigdel $B^{2}$}

${ }^{1}$ Lecturer, ${ }^{2}$ Associate Professor, Department of Pathology, Patan Hospital, Patan Academy of Health Sciences.

\section{ABSTRACT \\ Background}

Abnormal uterine bleeding may be defined as changes in frequency of menstruation, duration of flow or amount of blood loss. Early accurate diagnosis and proper treatment is essential to prevent progress to endometrial cancer.

\section{Objective}

This study was done to evaluate the histopathology of endometrium for identifying the endometrial causes of abnormal uterine bleeding.

\section{Method}

This was a retrospective study done in department of pathology, Patan Hospital from 1 August 2011- to 31 July 2012; total 413 cases were included in this study.

\section{Results}

The age of the patients ranged from 19 to 70 years. The most common clinical presentation was menorrhagia ( $47.46 \%)$, followed by continuous bleeding (14.04\%) and metrorrhagia (13\%). The commonest histopathological diagnosis was secretory endometrium 128 cases (30.99\%), followed by proliferative endometrium 91 cases $(22.03 \%)$. Secretory endometrium was most commonly (52 cases) observed in 41-50 years age group followed by 43 cases in 30-40 years age group. Similarly proliferative endometrium was also most commonly seen in 41-50 age group (44 cases) followed by 31-40 years of age group (32cases). Malignant disease was most commonly seen in 51-60 years age group.

\section{Conclusions}

Abnormal uterine bleeding is most common in 21-30 years age group. The most common clinical presentation is menorrhagia followed by continuous bleeding. Secretory endometrium is the most common histopathological findings. Malignancy is more common in postmenopausal group. 


\section{INTRODUCTION}

Abnormal uterine bleeding (AUB) is one of the commonest conditions for which patients seek advice in the gynae outpatient department.AUB may be defined as changes in frequency of menstruation, duration of flow or amount of blood loss. ${ }^{1}$ The abnormal bleeding can be caused by a wide variety of disorders. AUB may be the symptoms of endometrial carcinoma in $8-50 \%$ of cases. ${ }^{2}$ It is estimated that $9-30 \%$ of women of reproductive age suffer from menorrhagia. ${ }^{3}$ Thus early accurate diagnosis and proper treatment is essential to prevent progress to endometrial cancer and preclude unwarranted hysterectomy without definitive diagnosis.

Endometrial sampling could be effectively used as the first diagnostic step in AUB, although at times, its interpretation could be quite challenging to the practicing pathologists. ${ }^{4}$

This study was done to evaluate histopathology of endometrium for identifying the endometrial causes of AUB.

\section{METHODS}

This was a retrospective study done in department of pathology, Patan Hospital. All the samples/slides of endometrial specimen from 1 August 2011- to 31 July 2012 were included in this study. Total 413 cases were included in this study. All the endometrial biopsies and curettages of women with abnormal uterine bleeding were included in this study. The tissue submitted to pathology department was processed. Paraffin blocks were prepared and tissue section cut. The sections were stained with hematoxylin and eosin stain (H\&E) and prepared for microscopic examination. After receiving the slides history including the name, age,symptoms of each patient noted in a proforma. After reviewing the slides the pattern of uterine histological changes identified and classified according to age groups. Data was analysed by using Statistical package for Social Sciences (SPSS) version17 for windows.

\section{RESULTS}

Table .I: Age and number of the patients

\begin{tabular}{|l|c|c|}
\hline Age(Years) & $\begin{array}{c}\text { Number of } \\
\text { patients }\end{array}$ & Percentage \\
\hline$<20$ years & 75 & $18.03 \%$ \\
21-30 years & 118 & $28.37 \%$ \\
31-40 years & 97 & $23.32 \%$ \\
41-50 years & 86 & $20.67 \%$ \\
51-60 years & 32 & $7.69 \%$ \\
61-70 years & 08 & $1.92 \%$ \\
$>70$ years & 0 & 0 \\
Total & 413 & $100 \%$
\end{tabular}

The age of the patients studied were ranged from 19 to 70 years. Maximum 118 (28.37\%) patients with abnormal uterine bleeding presented in age group 21-30 years. .

\section{Graph. I: Distribution of cases according to clinical presentation.}

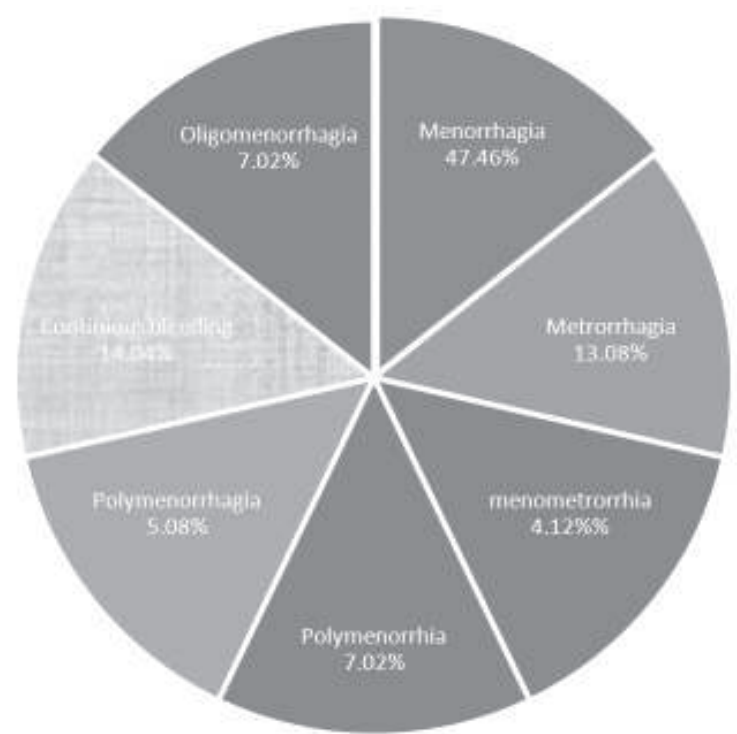

The most common clinical presentation was menorrhagia (47.46\%), followed by continuous bleeding (14.04\%) and metrorrhagia(13\%). 
Journal of College of Medical Sciences-Nepal, 2013, Vol-9, No-2,

Table. II: Distribution of AUB patients according to Histopathological pattern.

\begin{tabular}{|l|c|c|}
\hline Histopathological Pattern & No.of Patients & Percentage \\
\hline Proliferative & 91 & $22.03 \%$ \\
\hline Secretory & 128 & $30.99 \%$ \\
\hline Hyperplasia & 24 & $5.8 \%$ \\
\hline Endometritis & 32 & $7.75 \%$ \\
\hline Polyp & 6 & $1.45 \%$ \\
\hline Exogenous Hormone & 4 & $0.97 \%$ \\
\hline Disordered proliferative & 29 & $7.02 \%$ \\
\hline Atrophic & 6 & $3.87 \%$ \\
\hline Carcinoma & 12 & $2.91 \%$ \\
\hline Complications of Pregnancy & 66 & $15.98 \%$ \\
Inadequate & 5 & $1.21 \%$ \\
Total & 413 & $100 \%$ \\
\hline
\end{tabular}

The commonest histopathological diagnosis observed was secretory endometrium 128 cases( $30.99 \%)$ followed by proliferative endometrium 91 cases $(22.03 \%)$ and complication of pregnancy 66 cases(15.98)\%.

Table III. Histopathological distribution of AUB patients according to age group

\begin{tabular}{|c|c|c|c|c|c|c|}
\hline HistopathologicalFindings & $<20 y r s$ & 21-30yrs & 31-40yrs & 41-50yrs & 51-60yrs & 60-70yrs \\
\hline Proliferative & 2 & 11 & 32 & 44 & 2 & 0 \\
\hline Secretory & 1 & 30 & 43 & 52 & 2 & 0 \\
\hline Hyperplasia & 0 & 1 & 7 & 15 & 1 & 0 \\
\hline Endometritis & 0 & 8 & 9 & 14 & 1 & 0 \\
\hline Polyp & 0 & 1 & 2 & 3 & 0 & 0 \\
\hline Exogenous hormone & 0 & 1 & 1 & 2 & 0 & 0 \\
\hline Disordered proliferative & 0 & 3 & 9 & 16 & 1 & 0 \\
\hline Atrophic & 0 & 0 & 0 & 6 & 8 & 2 \\
\hline Complications Of Pregnancy & 11 & 32 & 21 & 2 & 0 & 0 \\
\hline Carcinoma & 0 & 0 & 0 & 4 & 6 & 2 \\
\hline Inadequate & 1 & 0 & 3 & 1 & 0 & 0 \\
\hline Total & 413 & & & & & \\
\hline
\end{tabular}

Secretory endometrium was most commonly (52 cases) observed in 41-50 years age group followed by 43 cases in 30-40 years age group. Similarly proliferative endometrium was also most commonly seen in 41-50 age group (44 cases) followed by 31-40 years of age group (32cases). 
Shrestha S et al. Study of endometrial Status of Patients with

\section{DISCUSSION}

Abnormal uterine bleeding is defined as any bleeding from uterus other than menstrual bleeding. Abnormal uterine bleeding could be caused by a wide spectrum of local and systemic disorders represented by as aberrant physiologic status at one hand to uterine malignancy at the other. ${ }^{5}$

Endometrial cancer, the most frequent gynaecologic malignancy in the western world, develop through preliminary stages of endometrial hyperplasia. ${ }^{4}$ The previous study has shown that $10-20 \%$ of endometrial hyperplasias progress to carcinoma when left untreated. Thus correct diagnosis is crucial to plan an optimal treatment and to prevent endometrial cancer development. ${ }^{6}$

In the study the age of the patients studied ranged from 19 to 70 years. Out of 413 patients 32(7.74\%) were postmenopausal and 381(92.25\%) were premenopausal .Maximum numbers 118(28.37) of patients were in the age group of 21-30years.In the study done by Ysuf et $\mathrm{al}^{7}$ and Muzaffar et al, ${ }^{8}$ highest incidence of AUB was found in 41-50yrs age group.

The most common clinical presentation was menorrhagia (47.46\%), followed by continuous bleeding (14.04\%), and Metrorrhagia(13.08\%). In a similar study done by Jairajpuri $\mathrm{ZS}$ et $\mathrm{al}^{9}$ the most common clinical presentation was menorrhagia (41\%) followed by metrorrhagia (18\%) and menometrorrhagia (14\%) .Menorrhagia as a common complaint has often been reported in literature, it varied between $51.95 \%$ and $53.3 \%$ observed, ${ }^{10,11}$ which is higher than those observed in present study. However in another study, Moghal $^{12}$ reported $41 \%$ only. In most of the other study metrorrhagia is reported as the second most clinical presentation however in our study continuous bleeding was found to be the second most common presentation $(14.04 \%)$.

In Histopathological evaluation, the commonest diagnosis observed was secretory endometrium 128 cases $(30.99 \%)$, followed by proliferative endometrium 91 cases $(22.03 \%)$. The similar findings were observed by Jaipuri ZS et al ${ }^{9}$.In their study the commonest histopathological finding was secretory endometrium( $28.9 \%$ ) closely followed by proliferative endomtoreium (24.9\%).Our study was in concordance with study done by Abdullah LS, Bondagji NS ${ }^{13}$ in which $24.9 \%$ cases of secretory endometrium reported as the commonest diagnosis followed by $21.7 \%$ of proliferative endometrium.

In our study secretory endometrium was most commonly (52 cases) observed in $41-50$ years age group followed by 43 cases in $30-40$ years age group. Similarly proliferative endometrium was also most commonly seen in 41-50 years age group (44 cases) followed by 31-40 years of age group (32cases) . In a study done by Bhatta S,Sinha AK 14 secretory endometrium was most commonly observed in 40-49 y ears age group and proliferative endometrium was also most common in 40-49 years age group.

12 patients in our study diagnosed as malignancy. Malignant disease was most commonly seen in 5160 years age group. In our study malignancy was most commonly found in post menopausal age group patients in comparision to premenopausal patients .Similar finding was reported by Dangal 
G. ${ }^{2}$ In our study very low percentage of cases were reported as malignancy .In a study done by Dhakal et al ${ }^{15}$ in BP Koirala Memorial cancer Hospital ,Chitwan endometrial carcinoma was only $2 \%$ of all gynecological cancers.

\section{CONCLUSION}

AUB is most common in 21-30 years age group.The most common clinical presentation is menorrhagia followed by continuous bleeding. Benign lesion was seen in most of the patients. Secretory endometrium was the most common histopathological findings. Malignancy is more common in postmenopausal group.

\section{REFERENCES}

1. Munro MG.Abnormal uterine bleeding in the reproductive years: Pathogenesis and clinical investigations .J Am Assoc Gynecol lapros 1999;6:393-416.

2. Dangal G. A study of endometrial of patients with abnormal uterine bleeding at Chitwan. KUMJ 2003; 1:110-2.

3. Dadhania B, Dhurva G, Agrawal A, Pujara K. Histopathological study of endometrium in dysfuctional uterine bleeding. Int $\mathrm{j}$ Res Med.2013;2(1);20-24.

4. Ghani N.A.,Abdul razak A.A.,Abdullah E.M. Abnormal Uterine bleeding : A Histopathological study.World Research Journal of Clinical Pathology,vol 1,issue 1,pp 06-08.

5. Khan S.,Hameed S., Umber A.(2011) Annals, 17(20), 166-170.

6. Anne Orbo A., Marit Arnes M., Hancke C.,et al.(2008) Gynaecological Oncology,111 68-73.
7. Yusuf NW,Nadeem R, Yusuf AW.Dysfuctional Uterine bleeding : A retrospective clinicomorphologicalstudy over two years.Pak J Obstet Gynaecol 1996;9(1):27-30.

8. Muzaffar M,Akhtar KA,Yasmin S,Mahmood Ur Rehaman,Iqbal W,Khan MA.Menstrual irregularities with excessive blood loss : a clinicopathological correlation.J Pak Med Assoc.2005;5(11): 486-489..

9. Zeeba S.Jairapuri,S.Rana and S. Jeteley : Atypical uterine bleeding- Histopathological audit of endometrium A study of 638 cases.Al Ameen J Med Sci 2013; 6(1): 21-28.

10. Bhosle A,Fonseca M.Evaluation and Histopathological correlation of abnormal uterine bleeding in perimenopausal women.Bombay Hospital Journal 2010;52:69-72.

11. Takreem A,Danish N,Razaq S. Incidence of endometrial hyperplasia in 100 cases presenting with polymenorrhagia/ menorrhagiain perimenopausal women.J Ayub Med Coll Abbottabad2009;21(2):60-63.

12. Moghal N.Diagnostic value of endometrial curettage in abnormal uterine bleeding-a histopathological study.J Pak Med Assoc1997;47:295-299.

13. Abdullah LS,Bondagji NS. Histopathological pattern of endometrial sampling performed for abnormal uterine bleeding.Baharain Med Bull 2011;33(4):1-6.

14. Bhatta S, Sinha AK: Histopathological study of endometrium in abnormal uterine bleeding.Journal of Pathology of Nepal (2012)vol2,297-300.

15. Dhakal H. Histological pattern of Gynecological cancers.J Nepal Med Assoc 2009;48:301-5. 